\title{
Emergence of Multi Drug Resistant Strains of Eschetichia coli Isolated from Urinary Tract Infection
}

\author{
Shohreh Farshad*,1 ${ }^{1}$ Reza Ranjbar ${ }^{2}$, Mojtaba Anvarinejad ${ }^{2}$, Maneli Amin Shahidi ${ }^{1}$ and \\ Marziyeh Hosseini ${ }^{1}$
}

\author{
${ }^{1}$ Alborzi Clinical Microbiology Research Center, Shiraz University of Medical Sciences, Shiraz, Iran \\ ${ }^{2}$ Molecular Biology Research Center, Baqiyatallah University of Medical Sciences, Tehran, Iran
}

\begin{abstract}
A current phenomenon of great concern among the medical communities in developing countries is rising multi-drug resistant organisms, and the challenges of curing the infections in children. In this study, we evaluated the multi drug resistant strains of Escherichia coli isolated from urinary tract infection in children in southern Iran. Totally, 90 strains of $E$. coli were collected from urine samples of the children, aged from 1 month to 14 years, referred to Motahary Hospital of Jahrom, Iran. After confirmation of the urine cultures which were expressive of urinary infection, gram stain and biochemical differential test were done for the isolates and their susceptibility patterns to different antibiotics were determined by standard disk diffusion method. The antibiogram patterns of the isolates showed a high percentage of multi drug resistance to ampicillin, co-trimoxazole and tetracycline which was repeated among 13 strains. With regard to the present data and high percentage of multi drug resistant strains of $E$ coli, regular monitoring antimicrobial drug resistance in different areas is necessary to prevent unsuitable utilization of drugs which is responsible for the emerging multi drug resistant strains.
\end{abstract}

Keywords: E coli, MDR, children, UTI, sensitivity.

\section{INTRODUCTION}

E. coli, known as UPEC, is the most prevalent extra digestive pathogen causing UTI in children and accounts for about $80-90 \%$ of the community acquired cases [1-3]. The exact prevalence rate of UTI is not clear yet, and varies with the age and gender of the individuals. Eighty percent of the girls and $20 \%$ of the boys stand the chance of infections including pylonephritis and cystitis at least once in their childhood $[4,5]$. A remarkable increase in antibiotic resistance among the E. coli isolates has been observed during the last few years [6]. Such rising resistance is due to mechanisms of mutation and then resistance gene transfer by transport means. Since a plasmid or transposon can carry several resistance indexes, resistance to several antimicrobial agents may be acquired simultaneously and results in multiple drug resistant (MDR) organisms [7-10].

MDR bacteria, thus, refers to those which are resistant to a vast range of antibiotics with structural independence (at least to three or more antibiotics). Nowadays, a big concern among the medical and clinical practitioners is the emerging MDR organisms and their associated complications in developing countries [11]. These conditions make the treatment more challenging and many even threaten the respective patients' lives.

Considering the majority of UTI cases caused by E. coli and increasing use of antibiotics followed by growing

*Address correspondence to this author at the Alborzi Clinical Microbiology Research Center, Shiraz University of Medical Sciences, Nemazee Hospital, Shiraz 71937-11351, Iran; Tel: +98 711 6474264;

Fax: +98 711 6474303; E-mail: farshads@ sums.ac.ir resistance in bacteria and emerging MDR strains, it seems necessary to conduct a regional research into the resistance patterns of the bacteria.

The present study seeks to investigate and identify the MDR patterns of the uropathogenic E. coli strains in Jahrom, southern Iran. The results can help adopt more effective strategies for the UTI treatment in the region and consequently reduce the increasing MDR organisms.

\section{METHODOLOGIES}

In this cross-sectional study, E. coli strains in the urine samples of children aged 1 month- 14 years (mean 21.8 \pm 26.9 months), were collected using midstream or urine bag in Motahary Hospital of Jahrom during one year. Diagnosis was made by the hospital personal and medical staff based on clinical findings and lab results. Children with flank pain, temperature above $38.5^{\circ} \mathrm{C}$, and neonates with septicemia indicating pylonephritis and disuria, urinary frequency, upper pubic pain suggestive of cystitis, were enrolled in the study. It is worth noting that only the community acquired cases were considered so that those who developed infection $48 \mathrm{hrs}$ after hospitalization and those with hospitalization history one month prior to the sampling, were excluded from the study. Questionnaires containing information about sex, UTI history and symptoms indicating upper or lower infection were filled. The collected samples were immediately transferred to the lab for EMB and Blood agar culturing, and stored for $24 \mathrm{hrs}$ at $37^{\circ} \mathrm{C}$. Afterwards, the growth rates of higher than $10^{5}$ colonies were tested for diagnosis of UTI. The sensitivity levels of the isolates to the antibiotics were examined using disk diffusion method and based on the CLSI, 2006 criteria $[12,13]$. Sensitivity to the 
Table 1. Antibiotic Sensitivity of E. coli Strains Isolated from Children with UTI in Iran

\begin{tabular}{|c|c|c|}
\hline Antibiotic & Sensitivity of all isolates. $\mathrm{N}(\%)$ & Sensitivity of MDR strains. N (\%) \\
\hline Tetracycline & $68(70.8)$ & $64(97)$ \\
\hline Chloramphenicol & $34(35.4)$ & $33(50)$ \\
\hline Cefixim & 19(19.7) & $16(24.2)$ \\
\hline Ceforoxime & $18(18.7)$ & $16(24.2)$ \\
\hline Gentamicin & $15(15.6)$ & $12(18.1)$ \\
\hline Ceftazidime & $10(10.4)$ & $9(13.6)$ \\
\hline Nitrifurantoin & $3(3.1)$ & $3(3.1)$ \\
\hline Amikacin & $3(3.1)$ & $3(3.1$ \\
\hline Imipenem & $0(0)$ & $0(0)$ \\
\hline
\end{tabular}

14 antibiotics including gentamicin $(10 \mu \mathrm{g})$, tetracycline $(30$ $\mu \mathrm{g})$, ceftazidime $(10 \mu \mathrm{g})$, co-trimoxazole $(25 \mu \mathrm{g})$, imipenem (10 $\mu \mathrm{g})$, ciprofloxacin $(5 \mu \mathrm{g})$, norfloxacine $(10 \mu \mathrm{g})$, cefexime $(5 \mu \mathrm{g})$, amikacin $(30 \mu \mathrm{g})$, chloramphenicole $(30 \mu \mathrm{g})$, nalidixicacid $(30 \mu \mathrm{g})$, nitrofurantoin $(300 \mu \mathrm{g})$, cefuroxime $(30 \mu \mathrm{g})$, ampicillin $(10 \mu \mathrm{g})$ were measured in vitro.

\section{RESULTS}

Of the total collected samples, $90 \mathrm{E}$. coli strains were recovered and detected based on culture characterization, biochemical and morphological features. Sixty two and half percent of the patients were male and the rest were female with the mean age of $21.8 \pm 26.9$ months. As revealed, $49.2 \%$ of the patients were with cystitis and $50.8 \%$ with pylonephratitis.

Based on the antibiogram test results, the greatest resistance found in 77 samples $(85.5 \%)$ to ampicillin, followed sequentially by 73 isolates $(81.1 \%)$ to cotrimoxazole and $68(75.5 \%)$ to tetracycline. All the isolates were sensitive to imipenem. According to Table 2 those which were resistant to 3 or more antibiotics and considered as MDR, comprised $77 \%$ of all the strains. Forty five resistance patterns were recognized among the MDR strains. Only $8.3 \%$ of the strains were sensitive to all the antibiotics.

Among the 66 MDR strains, $19(21.1 \%)$ were resistant to three antibiotics, $18(20 \%)$ to four antibiotics, $10(11.1 \%)$ to five antibiotics, $6(7.7 \%)$ to six antibiotics and $12(13.3 \%)$ to seven or more antibiotics. The most frequent $(14.4 \%)$ phenotypical pattern that was resistant to ampicillin, tetracycline and co-trimoxazole were repeated among the 13 isolates. The greatest resistance among the MDR agents was against tetracycline $(97 \%)$, followed by ampicilin $(95 \%)$ and co-trimoxazole (93\%) (Table 1).

\section{DISCUSSION AND CONCLUSION}

Antibiotic therapy is the first and the foremost for UTI, in which the invasive agents are controlled. Therefore, a correlation between the overuse of antimicrobials and increasing emergence of resistant bacteria seems natural [14$16]$. Worldwide reports of antibiotic resistant $E$. coli isolates indicate the unwise and excessive consumption of antimicrobial drugs which in turn has brought about failure in treatment, and consequently concerns about the related issues in all nations including the developed and developing ones. As an example, TMP-SXT was conventionally used for uncomplicated cystitis in most regions, however, due to the resistance to it, floroquinolon and cephalosporin took its place and unfortunately after sometime resistance to these two drugs was also recognized and reported [6, 17]. There are also reports from some countries on $E$. coli strains resistant to betalactam, co-trimoxazole and ampicillin [1820]. The gradual increasing resistance of the strains to floroquinolon is another growing concern among clinical practitioners. Since most UTI patients, in particularly developing nations, can not afford the medical visits and lab tests, they recurs empirical therapies which are not effective enough. Studies also show that even in US and developed countries many antibiotics are prescribed and consumed unwisely [21, 22], which results in the emerging resistance [17]. The greatest resistance in the present study was to ampicillin, co-trimoxazole and tetracycline which were introduced by WHO in 2007 as the drugs of choice [23]. Reports from developed and developing nations such as Turkey, Senegal, Brazil, Slovenia, southern India and Australia are consistent with the present findings [17, 12, 24, 27]. The growing antimicrobial resistance may be due to unrational use of antibiotics and the transfer of resistance genes by transport means including antibiotic resistant 
Table 2. Antibiotic Sensitivity Patterns of MDR E. coli Strains Isolated from Children with UTI in Iran

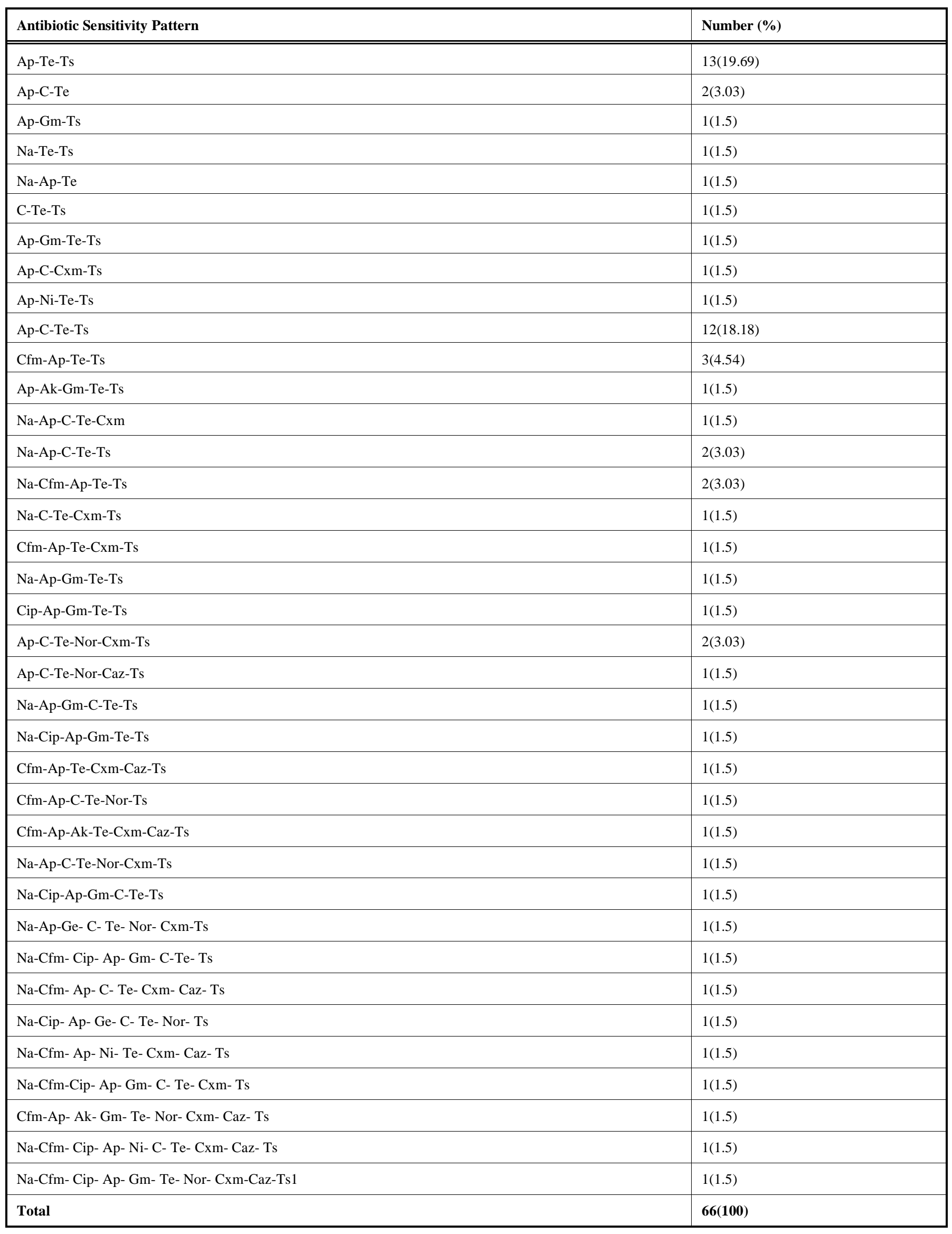


Table 3. Comparison of the Resistance to the Antibiotics Used in Treatment of Infections Caused by E. coli Strains in Different Countries

\begin{tabular}{|c|c|c|c|}
\hline Antibiotic & $\begin{array}{c}\text { Drug sensitivity in Iran in the } \\
\text { present study (\%) }\end{array}$ & $\begin{array}{c}\text { Drug sensitivity in Iran in the } \\
\text { past studies (\%) }\end{array}$ & Drug sensitivity in different countries (\%) \\
\hline \hline Co trimoxazole & 81.1 & 48.1 & India (48.3), USA (40.4), Austarlia (36) \\
\hline Tetracycline & 75.5 & 52.4 & India (10.3) \\
\hline Chloramphenicol & 37.7 & - & India (55.2), USA (29.3) \\
\hline Nalidixic acid & 26.6 & 16.8 & India (10.3), USA (8.4), Europe (7.7) \\
\hline Gentamicin & 16.6 & 14.8 & India (3.4), Europe (1.6), Spain (0.4), Hungary (0.3), \\
\hline Ceftazidime & 11.1 & 6.9 & India (22.4), Spain (16), England (6), Denmark (0.7), \\
\hline Ciprofloxacin & 8.8 & 18.3 & USA (11), Australia (5.8) \\
\hline Norfloxacin & 8.8 & 6.8 & Europe (1-4), Australia (2.5), India (0.0), USA (0.0 \\
\hline Amikacin & 3.3 & 1.8 & India (0.0), Australia (0.0), USA (0.0) \\
\hline Imipenem & 0 & 6.9 & \\
\hline
\end{tabular}

plasmids, bacterio-phages, transposons and integrons. Since a plasmid or transposon can carry several resistance indexes, simultaneous resistance to multiple antimicrobial agents may be developed and the result would be MDR organisms. For example, resistance to co-trimaxazole is usually accompanied by resistance to Ampicillin, cephalothin and Tetracycline.

To alleviate this suffering situation in developing nations, clinicians should prescribe antibiotics wisely and sufficiently and there should be periodic supervisions on the drug consumption by the respective organizations [14]. It is worth mentioning that in the present study $73 \%$ of the samples were resistant to three or more antibiotic, and most notably to ampicillin, tetracycline and co-trimoxazole. The MDR percentage varies with countries, in USA it was $7.1 \%$ in 2000 [28, 29] and in Slovenia 42\% in 2006 [25].

Different rates for MDR from Iran have been reported in 2003, it was 10.9\% [30] in Kashan, central Iran and 65\% in recent years $[31,14]$. Varying rates in different countries is indicative of how more antibiotic prescription is controlled. The minimum resistance, in the present study was found against imipenem, amikacin and nitrofurantoin. Adwan, Tariq and Mathai also reported the high sensitivity to imipenem as the drug of choice for UTI [26, 32, 33].

Table 3 shows the comparative levels of resistance to antibiotics in the infections caused by $E$. coli in different countries. According to the same table, the level of resistance to co-trimoxazole, tetracycline, ceftazidime and chloramphenicole in Iran is highest, compared to other nations [14, 26, 31], which might be due to several factors including improper policy in antibiotic prescription against bacterial infections. Unfortunately, lack of sufficient data about bacterial resistance to the antimicrobial agents in developing countries, including Iran, maybe responsible for the increasing emergences of MDR [14]. What is evident in developing nations, in comparison with Western and
European nations, is the growing resistance to the antibiotics such as ampicillin, co-trimoxazole, tetracycline, ceftazidime and gentamicin conventionally used in the treatment of infant with UTI caused by $E$. coli. To reduce the rate, urine culture and antibiotic sensitivity test prior to the onset of the main treatment seems highly recommended. Also, choice of antibiotic should be based on the site of infection at the pharmacodynamic spectrum of the drug. Isolation of the patients suspected for resistant strains is another effective measure in this arena. To fight against the bacterial resistance gene in their genomes, new generation and semi synthetic antibodies should be produced or even other therapeutic agents including bacteriophage be suggested.

In sum, the present finding, suggest that great percentage of $E$. coli isolates acts as the main risk for developing the resistance among the whole $E$. coli populations or closely related bacteria.

Further research on the characterization of resistant bacteria, their epidemiology and the spread of such bacteria by transport means and their relationship with prescription and consumption of antibiotics are warranted. Finally, insufficient attention and care about resistance mechanisms, spread and prevalence rates of them may cause presently effective antibiotics to become ineffective in the treatment of bacterial infections and consequently bring about serious challenges in medical practices.

\section{ACKNOWLEDGEMENT}

This research study was carried out on the reference number 84-22 of PACMRC, Nemazee Hospital, Shiraz, Iran. We express our thanks to the cooperative staff of the center. Our gratitude is to Dr Hassan Khajehei for his careful and invaluable linguistic copy editing.

\section{REFERENCES}

[1] Marrs, C.F.; Zhang, L.; Foxman, B.; Wicher, K.; Kosscinski, D. Escherichia coli mediated urinary tract infection: are there distinct 
uropathogene E. coli (UPEC) pathotypes culture media. FEMS Microbiol. Lett., 2005, 252, 183-189.

[2] Ejrnaes, K.; Sandvang, D.; Lundgren, B.; Ferry, S.; Holm, S.; Monsen, T.; Lundholm, R. Pulsed field gel electrophoresis typing of Escherichia coli strains from samples collected before and after pivmecillinam or placebo treatment of uncomplicated communityacquired urinary tract infection in women. J. Clin. Microbiol., 2006, 44, 1776-1781.

[3] Johnson, J.R.; Russo, T.A. Molecular epidemiology of extraintestinal pathogenic (uropathogenic) Escherichia coli. J. Med. Microbiol., 2005, 295, 383-404.

[4] Overturf, G.D. Urinary tract infection. In: Jenson HB, Baltimore RS. Ed. Pediatric infection disease, 2nd ed. Saunders Company, United States of America, 2002, pp.983-984.

[5] Mohkam, M.; Karimi, A.; Karimi, H.; Sharifian, M.; Armin, S.; Dalirani, R.; Abdollah, G.F. Urinary Interleukin_8 in acute pyelonephritis of children. Iranian J. Kidney Dis., 2008, 2, 193196.

[6] Li, Q.; Sherwood, J.S.; Logue, C.M. Characterization of antimicrobial resistant Escherichia coli isolated from processed bison carcasses. J. Appl. Microbiol., 2007, 103, 2361-2369.

[7] Hughes, V.M.; Datta, N. Conjugative plasmid in bacteria of the pre-antibiotic era. Nature, 1983, 302, 725-726.

[8] Davies. J. Inactivation of antibiotics and the dissemination of resistance genes. Science 1994, 264, 375-381.

[9] Labee-lund, T.M.; Sorum, H. Class 1 integrons mediate antibiotic resistance in the fish pathogen Aeromonas salmonicida worldwide. Microb. Drug Resist., 2001, 7, 263-272.

[10] Hall, R.M.; Collis, C.M. Mobile gene cassettes and integrons: capture and spread of genes by site-specific recombination. Mol. Microbiol., 1995, 15, 593-600.

[11] Guyot, A.; Barrett, S.P.; Threlfall, E.J.; Hampton, M.D.; Cheasty, T. Molecular epidemiology of multi-resistant Escherichia coli. $J$. Hosp. Infect., 1999, 43, 39-48.

[12] Yuksel, S.; Ozturk, B.; Kavaz, A.; Ozcakar, Z.B.; Acar, B.; Guriz, H.; Aysev, D.; Ekim, M.; Yalçınkaya, F. Antibiotic resistance of urinary tract pathogens and evaluation of empirical treatment in Turkish children with urinary tract infection. Int. J. Antimicrob. Agent., 2006, 28, 413-416.

[13] Clinical and Laboratory Standard Institute. Performance standards for antimicrobial susceptibility testing. M100-S16. Wayne, PA: CLSI. 2006.

[14] Ebrahimzadeh, M.A.; Mahdavee, M.R.; Vahedi, M. Antibiotic resistance in E. coli isolated from urine: A2-years study isolated from patient with urinary tract infections in Iran. J. Cell Tissue Res., 2005, 5(2), 445-448.

[15] White, P.A.; McIver, C.J.; Deng, Y.; Rawlinson, W.D. Characterization of two new gene cassette, aad A5 and dfr A17. FEMS Microbiol. Lett., 2000, 182, 265-269.

[16] Yu, H.S.; Lee, J.C.; Kang, H.Y.; Ro, D.W.; Chung, J.Y.; Jeong, Y.S.; Tae, S.H.; Choi, C.H.; Lee, E.Y.; Seol, S.Y.; Yoo Chul Lee, Y.C.; Cho, D.T. Changes in gene cassettes of class 1 integrons among $E$. coli isolates from urine specimens collects in Korea during the last two decades. J. Clin. Microbiol., 2003, 41, 54295433 .

[17] Guidoni, E.B.M.; Berezin, E.N.; Nigro, S.; Santiago, N.A.; Benini, V.; Toporovski, J. Antibiotic resistance patterns of pediatric community acquired urinary infection. Braz. J. Infect. Dis., 2008, $12,321-323$.
[18] Huovinen, P. Resistance to trimethoprim-sulfamethoxazole. Clin. Infect. Dis., 2001, 32, 1608-1614.

[19] Karki, T.; Truusalu, K.; Vainumae, I.; Mikelsaar, M .Antibiotic susceptibility patterns of community- and hospital-acquired Staphylococcus aureus and Escherichia coli in Estonia. Scand. J. Infect. Dis., 2001, 33, 333-338.

[20] Manges, A.R.; Tabor, H.; Tellis, P.; Vincent, C.; Tellier, P.P. Endemic and epidemic lineages of Escherichia coli that cause urinary tract infections. Emerg. Infect. Dis., 2008, 14, 1575-1583.

[21] Gonzales, R.; Malone, D.C.; Maselli, J.H.; Sande, M.A. Excessive antibiotic use for acute respiratory infection in the united states. Clin. Infect. Dis., 2001, 33, 757-762.

[22] Linder, J.A.; Huang, E.S.; Steinman, M.A.; Gonzales, R.; Stafford, R.S. Fluoroquinolone prescribing in the United States: 1995 to 2002. Am. J. Med., 2005, 118, 259-268.

[23] Wolff, O.; Maclennan, C. Evidence behind the WHO guidelines hospital care for children: what is the appropriate empiric antibiotic therapy in uncomplicated urinary tract infection in children in developing countries? J. Trop. Pediatr., 2007, 53, 150-152.

[24] Dromigny, J.A.; Nabeth, P.; Juergense, B.A.; Gros-Claude, J.D.P. Risk factors for antibiotic- resistant Escherichia coli isolated from community acquired urinary tract infection in Dakor, Senegal. $J$. Antimicrob. Chemother., 2005, 33, 89-94.

[25] Rijavec, M.; Starcic, E.M.; Ambrozic, A.J.; Reissbrodt, R.; Fruth, A.; Krizan-Hergouth, V.; Darja, Z.B. High prevalence of multidrug resistance and random distribution of mobile genetic elements among uropathogenic Escherichia coli of the four major phylogenetic groups. Curr. Microbiol., 2006, 53, 158-162.

[26] Mathai, E.; Grape, M.; Kronval, L.G. Integrons and multidrug resistance among E. coli causing community-acquired urinary tract infection in southern India. APMIS, 2004, 112, 159-164.

[27] Mehr, S.S.; Powell, C.V.; Curtis, N. Cephalosporin resistant urinary tract infection in young children. J. Paediatr. Child. Health 2004, 40(1-2), 48-52.

[28] Sahm, D.F.; Thornberry, C.; Mayfield, D.C.; Jones, M.E.; Karlowsky, J.A. Multi drug resistant urinary tract isolates of Escherichia coli: prevalence and patient demographics in the United States in 2001. Antimicorb. Agent Chemother., 2000, 45, 1402-1406.

[29] Gulsun, S.; Oguzoglu, N.; Inan, A.; Ceran, N. The virulence factors and antibiotic sensitivities of Escherichia coli isolated from recurrent urinary tract infections. Saudi Med. J., 2005, 26, 17551758.

[30] Moniri, R.; Khorshidi, A.; Akbari, H. Emergence of multidrug resistant strains of Escherchia coli isolated from urinary tract infections. Iranian J. Public Health 2003, 32(4), 42-46.

[31] White, P.A.; McIver, C.J.; Rawlinson, W.D. Integrons and gene cassettes in the entrobacteriaceae. Antimicrob. Agents. Chemother., 2001, 45, 2658-2661.

[32] Adwan, K.; Abu, H.N.; Adwan, G.; Jarrar, N.; Abu-Shanab, B.; AlMasri, M. Molecular epidemiology of antibiotic- resitant Escherichia coli isolated from hospitalized patient with urinary tract infection in Northen palestine. Pol. J. Microbiol., 2004, 53, 23-26.

[33] Tariq. N.; Jaffery. T.; Ayub, R.; Alam, A.Y.; Javid, M.H. Frequency and antimicrobial susceptibility of aerobic bacterial vaginal isolates. J. Coll. Physicians Surg. Pak., 2006, 16, 196-199. 